\title{
ANALISE DO DISCURSO DA EQUIPE DE SAÚDE E PACIENTE
}

\author{
Emilia Campos de Carvalho*
}

¿ARVALHO, E.C. de Análise do discurso da equipe de saúde e paciente. Rev. Esc. Enf. USP, v. 25, n. 1, p. 73-82, abr. 1991.

A presente análise visa considerar a ideologia institucional como possivel mantenedora da forma discursiva existente entre membros da equipe de saúde e pacientes. Retrata recortes discursivos de elementos da equipe Médica e de Enfermagem e pacientes oncológicos internados, em distintas situações interacionais: visitas clinicas, oriemtação, passagem de plantão $e$ outros. Encontrou-se que: a equipe decide se inclui ou não o paciente na conversação, independente de sua presença fisica; há assimetria nesta relą̧ão; há "apagamento" do paciente. Conclui-se que a força institucional existente mantém esta forma discursiva e dificulta mudaņ̧as nas relações interacionais entre estes elementos.

UNITERMOS: Comunicação. Relações interpessoais.

\section{INTRODUÇÃO}

A literatura tem evidenciado, segundo FAWCETT (1984) e LOPES (1988) um crescimento de artigos e livros cujas abordagens dizem respeito aos critérios sobre a utilização de resultados e a avaliação de uso de resultados de pesquisa. Não obstante este desapontar, ainda se apresentam insuficientes e continuam a retratar um distanciamento da prática.

Se tal distanciamento ocorre no campo da enfermagem em geral e se alternativas têm sido acalentadas para reverter este quadro, pode-se afirmar que o mesmo se passa em campos específicos do conhecimento utilizado, como a Comunicação.

A produção e a divulgação do conhecimento nesta área têm um quadro emergente de crescimento, evidenciando até o momento a sua não adequacidade na prática na maioria das vezes; busca-se, todavia, aprimoramento da situação existente. Oportunamente, ressalta OLIVEIRA (1985), a "transferência do saber, adquirido pela pesquisa, até que se incorpore à prática, demandará concentrado esforço" (p. 280).

Concorda-se que nesta investigação não se pode estar alheio à existência de fatores que permeiam esta situação. Nem sempre eles estão sob a responsabilidade do profissional, potencial usuário do conheci-

\footnotetext{
* Professor Associado do Departamento de Enfermagem Geral e Especializada da Escola de Enfermagem de Ribeirão Preto - USP.
} 
mento. Sabe-se que os membros da equipe de saúde estão numa instituição e a ideologia institucional confere condições para que se facilite ou não a utilização do conhecimento, no caso, sobre Comunicação. As considerações abordadas a seguir servem de subsídios para maior compreensão do pensamento da autora.

\section{O DISCURSO OBSERVADO}

Ao longo de sua trajetória profissional, a autora tem observado e participado de situações interacionais, passiveis de questionamento quanto à sua adequação, sob o ponto de vista da comunicação. Algumas delas dizem respeito à inserção do paciente oncológico como interlocutor no diálogo com elementos da equipe de saúde, em momentos que "se decide para" ou "sobre" o paciente.

Freqüentemente, estas situações têm sido justificadas pelos profissionais, face a não utilização dos conhecimentos produzidos e divulgação no âmbito da comunicação. Embora tais considerações possam ser pertinentes, cabe apontar a própria instituição como fator facilitador ou oponente a tal utilização. A instituição hospitalar é portadora de uma ideologia capaz de influenciar e, por vezes, determinar a comunicação entre seus membros. Face às condições sócio-político-históricas, tais instituições têm-se revelado autoritárias, normativas, facultando a seus membros determinado tipo de discurso.

Convém esclarecer que não se pretende aqui inviabilizar qualquer proposta de estudo ou de mudanças na comunicação entre equipes e paciente ou equipe-equipe; espera-se levantar a possibilidade de se considerar a influência do modelo de instituição hospitalar, o meio, no discurso de seus membros. Para tanto alguns cortes discursivos serão analisados.

Busca-se, desta forma, identificar mais uma possivel variável interveniente na utilização do conhecimento pelos membros da Enfermagem.

$\mathrm{Na}$ elaboração desta análise, utilizou-se, como corpus, os registros, com gravador, das falas de pacientes, enfermeiros, médicos, estudantes, membros da equipe de enfermagem, em diversas situações - passagem de plantão, visita clínica, orientação de pacientes, conversas informais com pacientes e diálogos, durante procedimentos terapêuticos - realizadas todas dentro do contexto hospitalar, relacionadas ao paciente oncológico.

Após a gravação estes dados foram transcritos e selecionados alguns recortes para para a presente abordagem.

As ocorrências observadas possibilitaram a inclusão do paciente no espaço onde a interação se realizava, através de sua "prestnça física". Sucede, porém, que nem sempre esta condição era "suficiente" para que os pacientes participassem dos diálogos. 
E comum aos elementos da equipe de saúde comentar "sobre" o paciente e não "com" o paciente aspectos que lhe dizem respeito. A participação do paciente no diálogo, inúmeros são os registros onde lhe era solicitado "aguarde um porquinho que depois conversamos com você" ou então "já sabemos deste seu problema", ou ainda "depois eu volto para conversar com a senhora".

Algumas situações já incorporadas à dinâmica de hospitais de ensino, como a visita clínica, predispõe a maior incidência de fatos como os descritas. Pode-se formular a hipótese de que o cerne da interação numa visita clínica é "o ensino da equipe", "a comunicação entre equipe" e não "o diálogo com o paciente".

Acreditando seja esta discussão de vasta amplitude, no presente trabalho ela vem subsidiar a reflexão sobre o possivel efeito negativo, a nível emocional, que o paciente virá a sofrer. A cena mais comum nestes casos é a de um grupo de elementos da equipe de saúde, conversando, examinando, discutindo e decidindo sobre a pessoa do paciente ou sua enfermidade; contudo não lhe é permitida a participação neste processo, quer por não entender o que é dito, ou por não lhe "ser permitido" dialogar com os presentes

Alguns exemplos poderão elucidar tais considerações:

\section{SITUAÇAO A - Visita Clínica}

$E_{1}$ e $E_{2}=$ Elementos da equipe de saúde.

$P=$ Paciente.

$E_{1}-O$ que ela tem?

$E_{2}=$ Está fazendo diarréia.

$P=F a z$ um mês hoje que eu cheguei aqui.

$E_{1}=$ Quem está cuidando dela? Pega a papeleta.

$P=A$ barriga dói, tá assim muito...

$E_{1}=$ Veja $b$ que prescreveram ontem (com finalidade de identificar analgésico). Precisa conversar com a paciente. Vamos lá: conversar e cuidar, viu! (sairam do ambiente)

\section{SITUAÇAO B - Visita Clinica}

$E_{1}$ e $E_{2}=$ Elementos da equipe de saúde.

$P$ - Paciente.

$E_{1}=$ Com relação à parte cardio-respiratória? 
$E_{\boldsymbol{z}}=$ Ele já tem três ecos, tem exame inicial, o atrito diminui, mas ele piorou! A hepatomegalia piorou, a dispnéia piorou, o edema do membro inferior piorou!

$P$ - (permanece deitado, olhando para o leito).

Observa-se que a presença física do paciente não o caracteriza como um interlocutor no diálogo. Quando ele "tenta" participar, as regras para manter uma conversação não são respeitadas. $O$ próprio paciente poderia "dar informações", mas não é este o objetivo, nas situações descritas.

Conforme menciona ORLANDI (1978), 'o discurso é visto como uma prática entre sujeitos, que reflete uma historicidade, apresentando relação de forças entre os mesmos, relação de sentido e produzindo em determinadas condições onde se considera: quem fala (lugar), onde fala (espaço), quando fala (tempo), o que fala (referente), como fala (formulação) e para quem fala (para que lugar).

Pela relação de forças, entende-se que haja relação necessária entre um discurso e o mecanismo social extralinguístico: quando se diz algo, sempre se diz de um lugar na sociedade. Este lugar faz parte da significação.

A relação de sentido institui que todo discurso reenvia a outro. Desta forma o discurso sempre se instala sobre os discursos anteriores.

Deve-se ainda considerar a antecipação, ou seja, a estratégia do discurso. Todo discurso pressupõe a capacidade de prever do locutor. Logo, o locutor procura levar ou regular as respostas do ouvinte.

As condições de produção do discurso podem ser definidas como as circunstâncias de sua realização: os seus protagonistas e seu objeto.

O conhecimento das circunstâncias do discurso entre membros da equipe e pacientes oncológicos pode gerar maior entendimento da prática de enfermagem nesta área.

Convém ater-se também às rclações existentes entre os elementos do grupo. Faz-se referência, aqui, às relações de poder que podem interferir, durante a visita clínica, com vários elementos de diferentes hierarquias funcionais, na conversação entre um enfermeiro e um paciente, por exemplo, ou de um médico-residente e paciente. Trata-se de reconhecer a existência de uma hierarquia implicita entre os elementos da equipe de saúde que atuam em instituições semelhantes às observadas.

Tudo indica que esta hierarquia apresenta o modelo: médico docente $>$ residente $>$ enfermeiro $>$ demais elementos da equipe de enfermagem $>$ paciente. Sabe-se que esta ordenação se mantém, mesmo quando faltam elos nesta cadeia, ou seja, docente $>$ residente ou enfermeiro > paciente e outros. 
Por se tratar de hospitais-escolas, as instituições estudadas, a elemento aprendiz (graduandos do curso médico ou de enfermagem) acaba sendo inserido nesta hierarquia e acima do nivel do paciente. Ex.: docente $>$ aprendiz $>$ paciente.

Neste caso, assim como em vários outros, tanto o docente como o aprendiz estabelecem a assimetria pelo dominio da competência, independendo do fator idade, geralmente mais elevado nos pacientes, nas situações observadas.

A relação de dominação-submissão entre enfermeiros e demais categorias de enfermagem já foi citada por ROCHA, SILVA, ALESSI (1985) ao examinarem os discursos de publicações da área materno-infantil; acredita-se poder ser esta relação estendida a outras áreas.

Quanto à condição sócio-econômica, a maioria dos pacientes apresentava nivel baixo, com pequeno grau de instrução. Estudos mais profundos poderiam mostrar se estas condições sócio-econômicas são muito diferentes das que vivem alguns elementos (atendentes, auxiliares) da equipe de enfermagem.

Acontecendo ser o nível sócio-econômico e o grau de instrução do paciente mais elevado que o habitual, ocorria tentativa de participação mais freqüente nos diálogos. Assim, observa-se que, em alguns momentos o paciente busca alterar esta hierarquia, tentando participar das decisōes sobre sua pessoa, prevalecendo, porém, a estrutura hierárquica anterior.

SITUAÇAO C - Durante avaliação do paciente:

$E$ - Elemento da equipe.

$P$ - Paciente.

$P$ - E o exame de sangue, como está?

$E$ - Tá bom, mas, o senhor não tem que se preocupar com isso, com o exame.

$P$ - Não, mas... (é interrompido).

$E$ - Não se preocupe.

$P$ - Não é isso!

$E$ - Vocé tem que se preocupar em ficar tranqüilo, procurar se alimentar na medida do possivel. Procura descansar o máximo possivel (é interrompido pelo paciente).

$P-N a \tilde{o} !$

E - Esqueça essas coisas!

$P$ - Você não está entendendo. Eq que conforme o exame... (é interrompido). 
$E$ - Eu sei, eu sei! O que fazer vai ser decidido ainda. Se tiver que tirar (o soro) tira, senão, não tira.

$P$ - Não, mas é que...

$E$ - Entendeu? (pausa)

$E$ - Fica tranqüillo!

$P$ - Eu estou. É que toda hora aparece uma coisa nova. É dor no fígado. Eu sou paciente, você pensa o quê?

$E-E u$ sei.

$P$ - Eu sou o paciente!

$E$ - Não é isso, eu só acho que o senhor está preocupado com certas coisas que o senhor não tem que ficar preocupado.

$P-N \tilde{o} \ldots$

$E$ - Deixe que a gente se preocupe com isso.

Nesta situação, observa-se a hierarquia do poder bastante acentua$\mathrm{da}$, onde o paciente "não tem que ficar preocupado". Vários exemplos com este foram observados onde o uso da competência pela equipe de saúde é constante.

Patenteia-se o distanciamento do paciente pela forma imperativa, não permissão de falar, uso do tratamento "senhor" dentre outros.

Segundo ORLANDI (1987) há três tipos de discurso: o lúdico, o polêmico e o autoritário. Expressa a distinção entre eles, a partir do referente e dos participantes do discurso, ou seja, o objeto do discurso e os interlocutores. No discurso autoritário o referente está ausente, oculto pelo dizer; não há interlocutores, mas um agente exclusivo, que pode ser levado à ordem, comando. O exemplo visto anteriormente parece se caracterizar por este tipo discursivo. Observa-se a quebra das leis do discurso propostas por DUCROT (1972), quais sejam: as leis do interesse, da utilidade $\mathrm{e}$ da informatividade (Lei do interesse: lei geral do discurso, segundo a qual não se pode falar legitimamente a outrem senão daquilo que the possa interessar. Lei da informatividade: se quiser informar, é preciso que o ouvinte desconheça 0 fato que se lhe aponta. Lei da utilidade: não se fala somente por falar, mas porque uma utilidade em fazê-lo).

Além ãessas leis há uma regulamentação destinada a cada categoria de atos de fala. Para se ordenar, interrogar, há uma certa relação hierárquica entre os interlocutores $\mathrm{e}$ isto também pode ser notado nos exemplos citados uma vez que o paciente está em posição hierárquica inferior.

O uso da cientificidade, através da Metalinguagem (linguagem técnica), de apropriação do cientista, feita pelo profissional, pode tam- 
bém ser estratégia, para reforçar autoridade, para "diluir" ou ocultar a informação. Assim, quando se diz " $E$ um portador de CEC, em $R H D$ " referindo-se a um paciente com Carcinoma Espino Celular a em regime de hïdratação e dieta, subentendendo-se que este não tem mais perspectivas terapêuticas.

$\mathrm{Na}$ situação de conversa informal com paciente observou-se alternância nas seqüências hierárquicas: aluno $>$ paciente e paciente $>$ aluno.

Cumpre esclarecer que as caracteristicas individuais de personalidade, de idade o fato da situação não ser estruturada, talvez tenham facilitado a constituição de uma simetria, não comum ao diálogo, na instituição hospitalar.

Outra situação observada comumente diz respeito aos significados de termos empregados. Alguns exemplos podem ser arrolados.

Concernente à questão do significado dos termos empregados, observa-se, às vezes, a discordância entre os elementos.

Conquanto este fato não represente problema a nivel de paciente, este comumente é atingido pelo maior ou menor entendimento dos termos. Vale relembrar aqui um exemplo da literatura, citado por CRULS (1920), sanitarista do início do século, comentando em suas crônicas, um caso interessante para reflexão; o autor cita a ocasião em que um funcionário de um hospital, que conhecia as condutas de um determinado grupo clínico, foi submetido à internação. No decorrer da mesma, após uma visita clínica, época em que o paciente estava muito grave, o responsável escreveu em sua papeleta a sigla G.C.P.N. O paciente, conhecedor que era da sigla, fugiu da instituição, pois entendeu que seu caso era sem esperança e o conteúdo da anotação dizia: Guarde Cadáver para Necrópsia.

É comum observar a reprodução de determinados "rótulos", sem, contudo, entender seus significados.

Dentre os dados coletados, destacam-se:

SITUAÇAOO D - Orientação de Paciente Portador de Neoplasia com Quadro Atual de Pericardite

$E$ - Elemento da equipe de saúde.

$P$ - Paciente.

$E$ - Como você tá vendo a evoluz̃ão da sua doença?

$P-Q$ uals

$E-A$ sua.

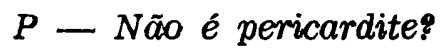

$E$ - Agora é! $O$ que é pericardite?

$P$ - Uma doença, doença pericardite. E..., tá... sei lá, parece que está estacionada. 
Este não entendimento pode também ocorrer com elementos da equipe. Dentre o "corpus" coletado, uma situação similar ocorreu, após uma passagem de plantão. Um funcionário novo no setor foi "explicar" ao paciente que ele tinha um tratamento proposto para o dia seguinte; indagou se ele sabia do fato e que se tratava de RTx. O paciente respondeu que "não estava tomandc nada" e o funcionário completou "quo deve ser remédio novo". Podemos apreender que, se em vez de ter dito, durante o plantão que "o paciente tem $R T x$ amanhã cedo", fosse verbalizado "radioterapia" ou "aplicação" termos também comuns no ambiente estudado, tanto o funcionário como 0 paciente saberiam do que se tratava.

Este aspecto merece maior atenção, tendo em vista o uso comum de siglas, palavras truncadas ou termos estrangeiros durante a conversação, no setor de oncologia, como, por exemplo, "apresenta sinal bad na mama esquerda", "paciente em 2: P.O, ndn" (segundo dia pós-operatório, nada digno de nota), "ACENTUADO desvio à esquerda do hemograma", se paciente for a "obi" (óbito), não liberar a "necro" (necrópsia).

Acredita-se que o fato de ocultação do diagnóstico e prognóstico permeia tal realidade. Este é um campo polêmico e alguns serviços, em especial de atendimento de pacientes adultos, adotam a conduta de expor ao paciente a real gravidade da situação; outros ocultam parcial ou totalmente tais informaçōes. A filosofia de cada serviço varia, mas todos afirmam buscar a melhor assistência a seus pacientes, dentro do seu entendimento de adequacidade. Todas as condutas estão sujeitas a críticas; seus resultados merecem estudos mais profundos. A fisolofia da instituição, qualquer que seja, reflete no discurso existente, trazendo em seu cerne a questão do poder.

A utilização desta estratégia de ocultação do significado dos termos usados assegura a comunicação entre a equipe, de forma a expressar o que ocorre com o paciente, sem que o mesmo participe, guardando nestes casos, a intenção de que "o paciente não compreenda o que é dito", ou que "não deva saber sobre o que é dito". Depreende-se, portanto, que a "decisão" de dizer ao paciente apenas o que a equipe julga adequado confirma que "o poder da informação" está nas mãos da equipe e, em especial, " $n a$ da equipe médica". Concorda-se, pois, com Good apud SETTE; RIBEIRO (1984), quando reporta estar a estrutura dialógica em relação fundamental com o poder.

Com respeito à simetria/assimetria entre os interlocutores, já parcialmente apresentada nos exemplos dados, passa pela análise da relação de poder entre os interlocutores.

Como lembra SETTE; RIBEIRO (1984), a "estrutura dialógica reflete as relações simétricas ou assimétricas dos interlocutores". Fatores externos à linguagem, tais como fatores ou condições externas dos interlocutores, definiveis por papéis e padrões sociais, implicariam na simetria ou assimetria da interação linguística propriamente dita; o 
médico é "dominante" entre os membros da equipe de saúde. Compreende-se, assim, que a simetria ou assimetria, relativas às posições assumidas pelos interlocutores do diálogo, estariam impostas " $a$ priori" como citam os autores mencionados anteriormente. Good apud SETTE; RIBEIRO (1984) também associa a relação do poder sócio-econômico ao poder "atribuido" aos interlocutores por outros fatores, como situações prefixadas por papéis sociais, personalidades dos interlocutores e autoridade no assunto proposto.

TFOUNI, CARVALHO, SCOCHI (1986), analisando diálogos entre enfermeiros e pacientes em situação de coleta de sangue, consideram a existência de uma relação assimétrica, determinada pelo enfermeiro. Este foi considerado como o que "domina" o diálogo e o paciente como aquele a quem regras não usuais de conversação são impostas.

$\mathrm{Na}$ ausência da pessoa do paciente, em situações de passagem de plantão, por exemplo, onde se comentava sobre o paciente, a relação era: do elemento da equipe que comunica $\rightarrow$ para os que recebem informações.

Esta ocorrência não se subordinava às condições sócio-econômicas, conhecimento técnico ou idade dos elementos da equipe. O conhecimento do que havia sucedido ao paciente, no período do plantão, parece ter interferência maior que as demais variáveis.

Em atenção aos achados desta investigação presencia-se que:

- Nas situações formais, como visita clínica, o paciente não foi incluído como interlocutor. Nas situações de orientação, ele participou do diálogo, mas nem sempre lhe foram dadas as informações de que necessitava e sim as que a equipe julgou serem adequadas, evidenciando estar aqui o poder de decisão;

- Em relação ao diálogo equipe-paciente houve assimetria. Somente na situação de "conversa informal" observou-se simetria entre os participantes;

- A terminologia empregada não foi comumente entendida pelos membros da equipe e paciente. Ela parece ser, deliberadamente, utiliezada para excluir o paciente do diálogo, através de seu não entendimento.

Verifica-se, portanto, o "apagamento" do paciente. O discurso na instituição hospital-escola entre médico-aluno, enfermeiro-aluno, enfermeiro-paciente, revelou-se autoritário.

A menção destes exemplos nesta pesquisa busca considerar a força da ideologia que permeia uma instituição hospitalar e sua influência no discurso entre seus membros, mediante uma observação crítica.

Fundamenta-se esta compreensão na necessidade de se identificarem as limitações existentes e as possíveis mudanças que permitam a utilização do conhecimento. 
CARVALHO, E.C. de Analysis of content of the health team and the patient. Rev. Esc. Enf. USP, v. 25, n. 1, p. 73-82, apr. 1991.

The present analysis considers an institutional's ideology as possible supporter of the discoursive form existing between the members of the health team and patients. It reveals discoursive parts of the members from the medical and nurse team and the oncologyc patients interned, in diferents interactional situations. It was observed that: - the staff is the one who decides if the patients is tobe include or not in the conversation, independently of his physical presence; there is assymmetry in this relationship; there is "turning-off" of the patient. It is concluded that the institutional power existent maintain discoursive form observed and it difficults the changes in the interactional-relationship between these elements.

UNITERMS: Communication. Interpersonal relations.

\section{REFERENCIAS BIBLIOGRÁFICAS}

CRULS, G. Coirara. Rio de Janeiro, s/ed., 1920. p. 51-74: G.C.P.N.

DUCROT, O. Dire et ne pas dire. Paris, Herman, 1972.

FAWCETT, J. Analysis and evaluation of conceptual models of Nursing. Philadelphia, Dawslo, 1984. $307 \mathrm{p}$.

LOPES, C.M. Exames gerais de qualificacão: um relato đe experiência a nivel de doutorado. Ribeirão Preto, EERP USP, 1988. nimeografado.

OLIVEIRA, M.J.R. Discurso de encerramento. SEMINARIO NACIONAL DE PESQUISA EM ENFERMAGEM, 4, São Paulo, 1985.

ORLANDI, E.L.P. A linguagem e sell funcionamento: as formas do discurso. Campinas, Pontes, 1987.

ORLANDI, E.L.P. Protagonista do/no discurso. Uberaba, 1978. p. 30-41.

ROCHA, S.M.M.; SILVA, G.B.; ALESSI, N.P. Caracteristicas do saber da enfermagem profissional na área materno-infantil: análise do seu discurso. In: SEMINARIO NACIONAL DE PESQUISA EM ENFERMAGEM, 3, Florianópolis, 1984. Anais. Florianópolis, Editora da UFSC, 1984. p. 173-94.

SETTE, N.M.D.; RIBEIRO, M.S.G.C.T. Interaşâo face-a-face: simetria/assimetria. Cad Wst. Linguist., n. 7, p. 87-109, 1984.

TFOUNI, I.V.; CARVALHO, E.C.; SCOCHI, C.G.S. Discurso, instituição e poder: análige da interação enfermeiro-paciente. Ribeirào Preto. 1986. Mimeografado.

Recebido em 08/04/90 